\title{
PREPARING OF DEMOCRATIC EDUCATION LEADERS IN ISLAMIC EDUCATIONAL LEADERSHIP PERSPECTIVE
}

\author{
Mawardi Lubis \\ Dosen Program Pascasarjana IAIN Bengkulu \\ Email ; lubis.mawardi@yahoo.co.id
}

\begin{abstract}
The objective of this research was to understand preparing of democratic education leaders in Islamic education leadership perspective. The approach be used in research was library research with a kind of qualitative research. The prosess of gathering data/information was used review method/technique through references review and including social media those connect to preparing democratic education leaders in Islamic education leadership perspective and the analytic technique was descriptive analytic technique. The research result indicates that preparing democratic education leaders in Islamic education leadership perspective had to be done the real actions for students, for every component of educational actvity had to be connected to theoretic and practice Islamic democratic leadership aspect.
\end{abstract}

Keywords: leader, education, democratic, leadership, Islamic

Abstrak: Tujuan penelitian ini adalah untuk mengetahui kiat-kiat mempersiapan pemimpin pendidikan demokratis dalam perspektif kepemimpinan pendidikan Islam. Pendekatan penelitian ini berupa pendekatan penelitian pustaka dengan jenis penelitian kualitatif. Metode/teknik pengumpulan data/informasi yang digunakan dalam penelitian ini adalah review technique, yakni review terhadap berbagai literatur dan termasuk media sosial yang terkait dengan topik dan permasalahan penelitian ini, yakni "mempersiapkan pemimpin pendidikan demokratis dalam perspektif kepemimpinan pendidikan Islam". Sedangkan teknik analisis yang digunakan adalah descriptive analytic technique, dimana data/informasi hasil review literatur diseleksi sesuai dengan kebutuhan dan diuraikan secara rinci dalam bentuk narasi. Hasil studi menunjukkan bahwa untuk mempersiapkan pemimpin pendidikan demokratis dalam perspektif kepemimpinan pendidikan Islam perlu dilakukan the real actions bagi pesrta didik, di mana setiap komponen aktivitas pendidikan ditekankan pada aspek kepemimpinan demokratis Islami baik secara teoretis maupun praktis.

Kata Kunci: pemimpin, pendidikan, demokratis, kepemimpinan, Islam

\section{Pendahuluan}

Krisis kepemimpinan sebagaimana dikemukakan oleh Wibawa (dalam Yuliati, 2013) melalui makalahnya yang disampaikan dalam kegiatan latihan kepemimpinan mahasiswa Universitas Negeri Yogyakarta menyatakan bahwa Indonesia mengalami krisis multidemensi sejak krisis moneter tahun 1997 dan krisis yang paling konkrit adalah krisis kepemimipnan. Oleh sebab itu, saat ini bangsa Indonesia sangat mengharapkan lahirnya pemimpinpemimpin yang konstruktif, yang mampu membawa perubahan-perubahan untuk memajukan bangsa. Namun kenyataannya, hari ini para pemimpin bangsa belum cukup menampilkan kepemimpinan yang demokratis, bahkan nyaris kurang memiliki integritas intelektual dan etik moral yang dapat dipertanggung jawabkan di depan publik. ${ }^{1}$

Hasil penelitian Mawardi Lubis (2013) dengan judul pengaruh gaya kepemimpinan kepala sekolah, partisipasi komite sekolah, dan soliditas guru terhadap efektivitas pengelolaan SD Negeri se-kota Bengkulu menemukan bahwa salah satu variabel yang berpengaruh langsung secara positif terhadap efektivitas pengelolaan satuan pendidikan ditentukan oleh faktor faktor gaya kepemimpinan (leader-

'https://journaal.unesa.ac.id/index.php/jptt/article/download /1390/ 960. Diunggah tanggal 4-10-2017. 
Mawardi Lubis I Preparing Of Democratic Education Leaders 108

ship style) yang dimiliki oleh para pemimpin pendidikan satuan pendidikan tersebut. ${ }^{2}$ Begitu banyak model, tipe, style, dan sifat-sifat kepemimpinan yang ada. Untuk itu para pemimpin pendidikan seharusnya memiliki wawasan yang luas tentang kepemimpinan, dengan harapan mereka dapat memilih dan menerapkan perilaku kepemimpinan mana yang efektif dalam upaya mewujudkan good management dalam pengelolaan program pendidikan, sehingga memberikan kemudahan dalam pencapaian tujuan pendidikan yang dicita-citakan.

Kepemimpinan merupakan sekumpulan dari serangkaian potensi (set or series of ability) dan sifat-sifat kepribadian (caracteristics of personality), termasuk di dalamnya kewibawaan, untuk dijadikan sebagai sarana dalam rangka meyakinkan yang dipimpinnya agar mereka mau dan dapat melakasanakan tugas-tugas yang dibebankan kepadanya dengan rela, penuh semangat, ada kegembiraan batin, serta merasa tidak terpaksa. ${ }^{3}$

Kepemimpinan dan manajemen ada hubungan yang integrated, dimana kepemimpinan adalah manifestasi yang nyata dari manajemen, bahkan dapat dikatakan bahwa inti dari manajemen adalah kepemimpinan.

Dalam istilah Arab, kepemimpinan diartikan dengan berbagai istialah seperti al-ri'aayah, al-imaarah, al-qiyaadah, al-za'aamah. Istilah-istilah tersebut adalah sinonim atau muraadif (memiliki satu makna). Sedangkan istilah kepemimpinan pendidikan, para ahli lebih memilih istilah qiyaadah tarbiyah. ${ }^{4}$

Kepemimpinan dalam Islam merupakan hal yang amatpenting. Oleh karenaitu, setiap pemimpin harus paham secara luas dan mendalam serta menguasai ilmu tentang kepemimpinan teoretis maupun praktis jika ingin menjadi seorang pemimpin yang amanah, yang benar-benar bertanggung jawab terhadap kepemimpinannya atau dengan kata lain disebut dengan pemimpin aspiratif (yang didambakan oleh semua orang).

Pemimpin menurut Fred E. Fiedler (dalam Purwanto) adalah individu yang berada dalam satu kelompok tertentu, dimana ia memberikan tugas-tugas pengarahan dan pengkoordinasian yang relevan dengan aktivitas-aktivitas kelempok tersebut. ${ }^{5}$

${ }^{2}$ Mawardi Lubis, "Pengaruh Gaya Kepemimpinan Kepala Sekolah, Partisipasi Komite Sekolah, dan Soliditas Guru Terhadap Efektivitas Pengelolaan SD Negeri se-Kota Bengkulu", Disertasi (Tidak dipublikasikan), 2013, h. 151.

${ }^{3}$ Nagalim Purwanto, Administrasi dan supervisi pendidikan, (Bandung PT. Remaja Rosdakarya, 2005), h. 26.

${ }^{4}$ Mujamil Qomar, Manajemen pendidikan Islam, (Malang : Erlangga, 2007), h. 268.

${ }^{5}$ Nagalim Purwanto, Administrasi dan supervisi pendidikan, ... h. 27
Dalam ajaran Islam, sekecil apapun komunitas yang ada diharuskan untuk memiliki seorang pemimpin mereka. Sebagai contoh, dalam pelaksanaan shalat berjama'ah harus dipimpin oleh seorang imam (pemimpin) meskipun mereka yang berjamaah tersebut hanya 2 (dua) orang (salah seorang di antara mereka berdua harus menjadi imam dan yang seorang lagi menjadi ma'mum/orang yang mengikut imam). Bahkan dalam al-Qur'an Allah swt berfirman bahwa setiap manusia diciptakan memiliki dua tugas yakni sebagai 'abid (penyembah Tuhan Allah swt $)^{6}$ dan sebagai khalifah fi alardh (pemimpin/pengelola bumi) ${ }^{7}$ dengan penuh tanggung jawab sebagaimana Nabi Muhammad saw bersabda dalam sebuah Hadits dari sahabat Ibn Umar ra yang diriwayatkan oleh Bukhari dan Muslim (muttafaqun 'alaih) : "Setiap kamu adalah pemimpin dan akan diminta pertanggung jawaban terhadap kepemimpinannya".

Penjelasan di atas menegaskan bahwa betapa pentingnya eksisistensi seorang pemimpin dalam hidup dan kehidupan ini, baik dalam kontek kehidupan beragama maupun dalam bernegara termasuk dalam lingkup kehidupan di dunia pendidikan.

\section{Metode}

Pendekatan penelitian ini berupa library research approach (pendekatan penelitian pustaka) dengan jenis qualitative research (penelitian kualitatif ). Metode/teknik pengumpulan data/informasi yang digunakan dalam penelitian ini adalah review technique (teknik tinjauan), yakni review terhadap berbagai literatur dan termasuk media sosial yang terkait dengan topik dan permasalahan penelitian ini, yakni "mempersiapkan pemimpin pendidikan demokratis dalam perspektif kepemimpinan pendidikan Islam”. Sedangkan teknik analisis yang digunakan adalah descriptive analytic technique (teknik analisis uraian), dimana data/informasi hasil review literatur diseleksi sesuai dengan kebutuhan (need) dan diuraikan secara rinci dalam bentuk narasi.

\section{Hasil Penelitian}

Seorang pemimpin yang baik harus memiliki perilaku positif, yang merupakan dimensi-dimensi pokok dari struktur fundamental kepemimpinan, yaitu berupa bantuan (support) atau tingkah laku yang memperbesar perasaan berharga seseorang

${ }^{6}$ Q.S. $51: 56$

Q.S. $2: 30$

${ }^{8}$ Salim Bahreisy, Riyadhus shalihin (Terjamahan Jilid I), (Bandung : PT Alma’arif, 1986), h. 528. 
Mawardi Lubis | Preparing Of Democratic Education Leaders 109

dan merasa dianggap penting, kemudahan interaksi (good interaction) atau tingkah yang memberanikan anggota-anggota kelompok untuk mengembangkan hubungan-hubungan yang saling menyenangkan, pengutamaan tujuan (goal priority) atau tingkah laku yang merangsang antusiasme bagi penemuan tujuan kelompok mengenai pencapaian prestasi yang baik, serta kemudahan bekerja (good management) atau tingkah laku yang membantu pencapaian tujuan dengan kegiataan-kegiatan seperti penetapan waktu, pengoordinasian, perencanaan, dan penyedian sumber-sumber seperti alat-alat, bahanbahan, dan pengetahuan teknis. ${ }^{9}$

Dimensi support, good interaction, goel priority, dan good management yang merupakan hal yang dianggap penting dalam struktur fundamental kepemimpinan perlu didukung oleh pendekatan dan model kepemimpinan, yakni ;

1. Pendekatan kepemimpinan

Pendekatan kepemimpinan antara lain sebagai berikut :

a. Pendekatan sifat-sifat (caracteristic approach), dimana seseorang menjadi pemimpin karena sifat-sifatnya yang dibawa sejak lahir, bukan karena dibuat- buat atau dilatih.

b. Pendekatan perilaku (behavioral approach), pendekatan yang berdasarkan pemikiran bahwa keberhasilan atau kegagalan pemimpin ditentukan oleh sikap dan gaya kepemimpinan yang dilakukan pemimpin yang bersangkutan.

c. Pendekatan situasional (situational approach), didasarakan atas asumsi bahwa keberhasilan kepemimpinan suatu organisasi atau lembaga tidak hanya bergantung pada atau dipengaruhi oleh perilaku dan sifat-sifat pemimpin saja.

2. Model kepemimpinan Model kepemimpinan antara lain sebagai berikut :

a. Model kepemimpinan kontingensi Fielder, keberhasilan seorang pemimpin tidak hanya ditentukan oleh suatu gaya kepemimpinan yang diterapkannya.

b. Model kepemimpinan tiga dimensi (threedimensional -model), menghubungkan tiga kelompok gaya kepemimpinan, yaitu : a) gaya dasar ; terpadu (integrated), pemisah (separated), pengabdi (dedicated), dan penghubung (related) b) gaya efektif ; eksekutif (executive), birokrat (bureaucrat), otokrat bijak (benevolent autocrat), dan pengembang (developer) b) gaya

${ }^{9}$ Nagalim Purwanto, Administrasi dan supervisi pendidikan, ... h. 29 tak efektif ; komporomis (compromiser), pelari (deserter), otokrat (autocrat), dan penganjur (missionary).

c. Model kontinum berdasarkan banyaknya peran serta bawahan dalam pengambilan keputusan. ${ }^{10}$

Beberapa pendekatan dan model kepemimpinan tersebut di atas dapat dijadikan suatu pertimbangan bagi seorang pemimpin dalam menjalankan tugas kepemimpinannya serta menyesuaikannya dengan kontek kepemimpinannya.

Seorang pemimpin perlu juga memahami tipe-tipe kepemimpinan yang secara umum dapat diketahui akan mempengaruhi sukses tidaknya seseorang dalam menjalankan kepemimpinannya, antara lain sebagai berikut :

1. Kepemimpinan yang otokratis, pemimpin bertindak sebagai diktator (bersifat memaksa) terhadap anggota-anggotanya

2. Kepemimpinan yang laissez faire, pemimpin yang termasuk tipe ini sama sekali tidak memberikan kontrol dan koreksi terhadap pekerjaan anggota-anggotanya/membiarkan orang-orang berbuat sekehendaknya

3. Kepemimpinan yang demokratis, dimana tipe ini memiliki sifat-sifat :

a. Dalam menggerakkan bawahan bertitik tolak dari pendapat bahwa manusia itu makhluk yang termulia di dunia ini.

b. Selalu berusaha menyingkronkan kepentingan dan tujuan organisasi dengan kepentingan dari tujuan pribadi bawahan.

c. Senang menerima saran, pendapat, dan kritik dari bawahan.

d. Mengutamakan kerja sama dalam mencapai tujuan.

e. Memberikan kebebasan seluas-luasnya kepada bawahan, dan membimbingnya.

f. Mengusahakan agar bawahan dapat lebih sukses daripada dirinya.

g. Selalu mengembangkan kapasitas diri pribadinya sebagai pemimpin. ${ }^{11}$

Tipe demokratis merupakan tipe kepemimpinan yang paling ideal, dan dianggap paling baik terutama untuk kepemimpinan dalam pendidikan, termasuk kepemimpinan dalam pendidikan Islam, yang diistilahkan dengan bilhikmah waalmau'idzatilhasanah. Sebagaimana firman Allah swt sebagai berikut : Serulah (manusia) kepada $48-50$ 
jalan Tuhanmu dengan hikmah dan pelajaran yang baik dan bantahlah mereka dengan cara yang baik. Sesungguhnya Tuhanmu Dialah yang lebih mengetahui tentang siapa yang tersesat dari jalanNya dan Dialah yang lebih mengetahui orang-orang yang mendapat petunjuk. ${ }^{12}$

Lebih lanjut, pemimpin dalam kontek pendidikan Islam harus memiliki sifat-sifat kepemimpinan berikut di bawah ini :

1. Ikhlas

Firman Allah swt : Padahal mereka tidak disuruh kecuali supaya menyembah Allah dengan memurnikan keta'atan kepadaNya dalam (menjalankan) agama dengan lurus, dan supaya mereka mendirikan shalat dan menunaikan zakat ; dan yang demikian itulah agama yang lurus. ${ }^{13}$

2. Ta'at kepada Allah dan RasulNya

Firman Allah swt : Dan ta'atilah Allah dan Rasul, supaya kamu diberi rahmat. ${ }^{14}$

3. Rendah hati dan sederhana (tawadlu')

Firman Allah swt : Dan janganlah kamu berjalan di muka bumi ini dengan sombong, karena sesungguhnya kamu sekali-kali tidak dapat menembus bumi dan sekali-kali kamu tidak akan sampai setinggi gunung. ${ }^{15}$

Dan selanjutnya Allah swt berfirman : Dan janganlah kamu memalingkan mukamu dari manusia (karena sombong) dan janganlah kamu berjalan di muka bumi dengan angkuh. Sesungguhnya Allah tidak menyukai orang-orang yang sombong lagi membanggakan diri. ${ }^{16}$

4. Menjauhkan diri dari hal-hal yang haram dan subhat (wara')

Firman Allah swt : (Ingatlah) di waktu kamu menerima berita bohong dari mulut ke mulut dan kamu katakan dengan mulutmu apa yang kamu tidak ketahui sedikit juga, dan kamu menganggapnya sesuatu yang ringan saja. Padahal dia pada sisi Allah adalah hina. ${ }^{17}$

Dan selanjutnya Allah swt berfirman : Sesungguhnya Tuhanmu benar-benar mengawasi. ${ }^{18}$

Firman Allah swt : ..., Dan tolong-menolonglah kamu dalam (mengerjakan) kebajikan dan takwa, dan jangan tolong-menolong dalam berbuat dosa dan pelanggaran. Dan bertakwalah kamu kepada Allah, sesungguhnya Allah amat berat siksanya. ${ }^{19}$
6. Sabar dan memiliki kestabilan emosi

Firman Allah swt : Hai orang-orang yang beriman, jadikanlah sabar dan shalat sebagai penolong$\mathrm{mu}$, sesungguhnya Allah beserta orang-orang yang sabar. ${ }^{20}$ Dan selanjutnya Allah swt berfirman : Hai anakku, dirikanlah shalat dan suruhlah (manusia) mengerjakan yang baik dan cegahlah (mereka) dari perbuatan yang mungkar dan besabarlah terhadap apa yang menimpa kamu. Sesungguhnya yang demikian termasuk hal-hal yang diwajibkan (oleh Allah). ${ }^{21}$

7. Percaya kepada diri sendiri (self confident) dan optimis

Firman Allah swt : Hai anak-anakku, pergilah kamu, maka carilah berita tentang Yusuf dan saudaranya dan jangan kamu berputus asa dari ramat Allah. Sesungguhnya tiada berputus asa dari ramat Allah, melainkan kaum yang kafir. ${ }^{22}$

8. Jujur, adil, dan dapat dipercaya

Firman Allah swt : Hai orang-orang yang beriman bertakwalah kamu kepada Allah, dan hendaklah kamu bersama orang-orang yang benar (jujur). ${ }^{23}$ Kemudian Allah swt berfirman : Sesungguhnya Allah menyuruh (kamu) berlaku adil dan berbuat kebajikan, memberi kepada kaum kerabat, dan Allah melarang dari perbuatan keji, kemungkaran dan permusuhan. Dia memberi pengajaran kepadamu agar kamu dapat mengambil pelajaran. ${ }^{24}$ Selajutnya Allah swt berfirman: Sesungguhnya Allah menyuruh kamu menyampaikan amanta kepada yang berhak menerimanya, dan (menyuruh kamu) apabila menetapkan hukum di antara manusia supaya kamu menetapkan dengan adil. Sesungguhnya Allah ádalah Maha Mendengan lagi Maha Melihat. ${ }^{25}$

9. Ahli dalam jabatan (expert)

Firman Allah swt : ... maka bertanyalah kepada orang yang mempunyai pengetahuan (expert) jika kamu tidak mengetahui. ${ }^{26}$

10. Bertanggung jawab (Responsibility/accountability)

Firman Allah swt : Dan janganlah kamu mengikuti apa yang kamu tidak mempunyai pengetahuan tentangnya, sesungguhnya pendengaran, penglihatan dan hati, semuanya itu akan diminta pertanggungan jawabnya. ${ }^{27}$

${ }^{16}$ QS. 31:18

${ }^{17}$ QS. 24:15

${ }^{18}$ QS. 89:14

${ }^{19}$ QS. 5:2 
Mawardi Lubis | Preparing Of Democratic Education Leaders 111

Firman Allah swt : ... Sesungguhnya janji Allah ádalah benar, maka janganlah sekali-kali kehidupan dunia memperdayakan kamu, dan jangan (pula) penipu (syaitan) memperdayakan kamu dalam (menta'ati) Allah. ${ }^{28}$

12. Qona'ah

Firman Allah swt : Dan tidak ada suatu binatang melata pun di bumi melainkan Allah-lah yang memberi rezkinya, dan Dia mengetahui tempat bedrdiam binatang itu dan tempat penyimpanannya. Semuanya tertulis dalam Kitab yang nyata (Lauh mahfuzh) ${ }^{29}$ Dan Allah swt berfirman : Dan orang-orang yang apabila membelanjakan (harta), mereka tidak berlebih-lebihan, dan tidak (pula) kikir, dan adalah (pembelanjaan itu) di tengah-tengah antara yang demikian. ${ }^{30}$

Agar sukses dalam kepemimpinannya, seorang pemimpin perlu didukung oleh berbagai faktor yang dapat mempengaruhi kepemimpinannya, antara lain :

1. Keahlian dan pengetahuan

2. Jenis pekerjaan atau lembaga

3. Sifat-sifat kepribadian pemimpin

4. Sifat-sifat kepribadian pengikut atau kelompok yang dipimpinnya

5. Sangsi-sangsi yang ada di tangan pemimpin. ${ }^{31}$

Seorang pemimpin harus menyadari bahawa dirinya memiliki peranan penting dalam kepemimpinannya, antara lain :

1. Sebagai perencana (planner)

2. Sebagai pelaksana (executive)

3. Sebagai seorang ahli (expert)

4. Mewakili kelompok (external group representative)

5. Mengawasi hubungan antar anggota kelompok (controller of internal relationship)

6. Pemberi ganjaran/pujian dan hukuman (purveyor of rewads and punishments)

7. Sebagai wasit dan penengah (arbitrator and mediator)

8. Merupakan bagian dari kelompok (exemplar)

9. Lambang kelompok (syimbol of the group)

10. Pemegang tanggung jawab para anggota kelompoknya (surrogate for individual responsibility)

11. Sebagai pencipta/memiliki cita-cita (ideologist)

12. Sebagai seorang ayah (father figure)

13. Sebagai 'kambing hitam' (scape goat)

${ }^{28}$ QS.31:33

${ }^{29} \mathrm{QS} .11: 6$

${ }^{30}$ QS. 25:67 59-61.

${ }^{31}$ Nagalim Purwanto, Administrasi dan supervisi pendidikan, ... hh
Seorang pemimpin harus menyadari bahawa dirinya memiliki peranan penting dalam kepemimpinannya, antara lain :

1. Sebagai perencana (planner)

2. Sebagai pelaksana (executive)

3. Sebagai seorang ahli (expert)

4. Mewakili kelompok (external group representative)

5. Mengawasi hubungan antar anggota kelompok (controller of internal relationship)

6. Pemberi ganjaran/pujian dan hukuman (purveyor of rewads and punishments)

7. Sebagai wasit dan penengah (arbitrator and mediator)

8. Merupakan bagian dari kelompok (exemplar)

9. Lambang kelompok (syimbol of the group)

10. Pemegang tanggung jawab para anggota kelompoknya (surrogate for individual responsibility)

11. Sebagai pencipta/memiliki cita-cita (ideologist)

12. Sebagai seorang ayah (father figure)

13. Sebagai 'kambing hitam' (scape goat)

Dari ke-13 peranan kepemimpinan tersebut di atas, barangkali sesuai dengan apa yang dikemukakan oleh bapak pendidikan kita, Ki Hadjar Dewantara, bahwa pemimpin yang baik haruslah menjalankan peranan di bawah ini :

1. Ing ngarso asung tulodo, di depan menjadi contoh

2. Ing madyo mangun karso, ditengah-tengan menjadi orang mampu membangkitkan semangat creativitas

3. Ing (Tut) hurí andayani, mampu memberikan motivasi. ${ }^{32}$

Berdasarkan penjelasan di atas (sebagai hasil penelitian atau review literatur) dapat disintesiskan bahwa menjadi seorang pemimpin yang baik atau efektif, maka ia harus kuat, amanah, dan bertanggung jawab terhadap kepemimpinannya. Artinya, ia harus memiliki fisik dan psikis yang sehat dan tangguh serta memiliki wawasan yang dalam dan luas tentang ilmu kepemimpinan baik secara teoretis maupun praktis.

\section{Pembahasan}

Studi Lewin dkk. (dalam Danim, 2010) menemukan bahwa kepemimpinan demokratis (democrative leadership) atau sering juga disebut dengan participative leadership pada umumnya merupakan gaya

${ }^{32}$ Nagalim Purwanto, Administrasi dan supervisi pendidikan, ... hh. 
Mawardi Lubis | Preparing Of Democratic Education Leaders 112

kepemimpinan yang paling efektif. Oleh karena itu, pemimpin demokratis menawarkan bimbingan kepada anggota serta berpartisipasi dalam kelompok dan memungkinkan menerima masukan dari anggota kelompok lainnya. Pemimpin demokratis/ partisipatif mendorong anggota kelompok untuk berpartisipasi, tapi mempertahankan keputusan akhir/final atas proses pegambilan keputusan (decision making). Anggota kelompok merasa dilibatkan dalam proses, lebih termotivasi, kereatif, dan inovatif. $^{33}$

Yuliati (2013) menjelaskan bahwa pemimpin demokratis adalah pemimpin yang egaliter, mengayomi, mendengarkan, dan berpihak pada bawahan, serta selalu membuat kebijakan yang populis. Namun, ia mengatakan bahwa sulitnya menemukan figur kepemimpinan efektif dan demokratis pada saat ini mengindikasikan adanya kebutuhan untuk menyiapkan atau mendidik calon-calon pemimpin masa depan dengan gaya kepemimpinan demokratis. Lebih lanjut, ia mengatakan bahwa dalam konteks ini lembaga pendidikan dipandang sebagai institusi yang paling baik untuk mempersiapkan dan mendidik calon-calon pemimpin masa depan yang demokratis. Jadi, untuk mempersiapkan pemimpin masa depan yang demokratis, lembaga pendidikan perlu membantu setiap peserta didik mengembangkan kemampuan untuk mengambil perspektif orang lain (perspective taking). ${ }^{34}$

Hasil riset Supriadi (1998) membuktikan bahwa gaya kepemimpian pendidikan yang demokratis memberikan kontribusi signifikan terhadap kualitas layanan dan kualitas pendidikan. Lebih lanjut ia mengatakan bahwa gaya kepemimpinan demokratis jauh lebih berpengaruh terhadap mutu pendidkan dari pada gaya kepemimpinan otoriter. Oleh karena itu, bisa dikatakan bahwa semakin demokratis kepala sekolah dalam memimpin sekolahnya, maka semakin tinggi mutu pendidikan yang dihasilkan. ${ }^{35}$

Hasil penelitian yang dilakukan oleh Lubis (2007) tentang implementasi nilai-nilai islami melalui manajemen berbasis sekolah (MBS) pada MAN model Bengkulu menemukan bahwa nilai-nilai Islami yang membingkai dimensi-dimensi manajemen dalam MBS di MAN model Bengkulu adalah nilai tauhid, kejujuran, amanah, toleransi, transparansi, kedisiplinan, dan lain-lain dalam semua aspek manajemen. Nilai-nilai Islami ini diimplementasi-

Sudarwan Danim, Kepemimpinan Pendidikan, ... h. 10.

${ }^{34} \mathrm{https}:$ //journaal.unesa.ac.id/index.php/jptt/article/ download/1390/960. Diunggah tanggal 4-10-2017.

${ }^{35}$ Oding Supriadi, Rahasia Sukses Kepala Sekolah, (Yogyakarta : LaksBang, 2010), h. 154. kan pada semua aspek dan bentuk kegiatan, baik pada tingkat dicision making maupun pada tingkat operasional atau implementasi suatu keputusan oleh semua pihak yang terkait. Implementasi nilainilai Islami yang dilakukan tanpa mengabaikan nilai-nilai modernitas lainnya selama nilai-nilai itu tidak bertentangan dengan nilai-nilai Islam. ${ }^{36}$

Kamudian, hasil penelitian kelompok yang dilakukan Lubis, dkk. (2011) tentang perilaku kepemimpinan kepala madrasah perempuan (studi kasus di MTs Mambaul Ulum Kec. Pondok Kubang Kab. Bengkulu Tengah) menemukan bahwa gaya kepemimpinan kepala madrasah perempuan MTs. Mambaul Ulum Kec. Pondok Kubang Kab. Bengkulu Tengah adalah gaya kepemimpinan demokratis, sehingga model policy making dan decision making yang terbuka melalui kesepakatan rapat menjadi prioritas. Walaupun ada penawaran dari kepala madrasah, namun aspek penyerapan aspirasi bawahan juga menjadi perhatian yang seimbang (bottomup). Hal ini memberikan pengaruh dan kontribusi yang sangat signifikan terhadap pencapaian efektivitas pengelolaan sekolah/madrasah.

Keberhasilan gaya kepemimpinan kepala madrasah perempuan yang demokratis ini dapat diukur dengan dua indikasi, yaitu kemampuan menjalankan roda organisasi dengan baik, menunjukkan berbagai prestasi yang telah dicapai dan juga mampu menjaga keberlangsungan organisasi dengan baik melalui daya kreativitas akal pikiran, sikap dan dorongan spiritual keagamaan berupa keikhlasan. ${ }^{37}$

Senada dengan penjelasan di atas, Mulyasa menyatakan bahwa kepala sekolah (pemimpin satuan pendidikan) yang demokratis memerankan diri sebagai pembimbing, pengarah, pemberi petunjuk, serta bantuan kepada para tenaga pendidik dan kependidikan. Keputusan yang diambil oleh kepala sekolah dilakukan berdasarkan musyawarah. ${ }^{38}$

Selanjutnya, para peneliti lain juga telah menemukan bahwa gaya kepemimpinan demokratis adalah salah satu gaya kepemimpinan yang paling efektif dan mengarah kepada produktivitas yang lebih tinggi, kontribusi yang lebih baik dari anggota kelompok, dan meningkatkan semangat kelompok.

${ }^{36}$ Mawardi Lubis, "Implementasi Nilai-nilai Islami melalui MBS pada MAN model Bengkulu", Sosio-Religia, vol. 9 (2) Yogyakarta 2010, hh. 505521.

${ }^{37}$ Mawardi Lubis, M. Syakroni dan Moch. Dahlan, "Perilaku Kepemimpinan Kepala Madrasah Perempuan" (studi kasus di MTs Mambaul Ulum Kec. Pondok Kubang Kab. Bengkulu Tengah), Manhaj Vol. 12 (1) Bengkulu 2012, hh. $64-68$.

${ }^{38}$ Mulyasa, Menjadi Kepala Sekolah Profesional, (Bandung : PT. Remaja Rosdakarya, 2006), h. 270. 
Pemimpin dengan gaya kepemimpinan demokratis mengedepankan perilaku kepemimpinan bahwa setiap orang diberi kesempatan untuk berpartisipasi, ide-ide dipertukarkan secara bebas, dan didorong untuk berpartisipasi dalam diskusi. Sementara proses demokrasi cenderung fokus pada kesetaraan kelompok dan aliran dengan bebas ide serta menawarkan bimbingan dan kontrol. Oleh karena itu, pemimpin demokratis yang baik memiliki ciri-ciri khusus, yakni meliki kejujuran, intelijen, keberanian, kreativitas, kompetensi, dan keadilan. ${ }^{39}$

Pendapat yang sama mengatakan bahwa pemimpin dengan democratic leadership style sering disebut enlightened leader karena menghargai dan menganggap orang lain. Pemimpin demokratis melibatkan partisipasi bawahan dalam pengambilan keputusan organisasi, bertindak berdasarkan kepercayaan (trust), integritas (integrity), kebersamaan (equality), keterbukaan (openness), dan saling menghargai (mutual respect).$^{40}$

Dalam rangka mempersiapkan pemimpin pendidikan demokratis ditinjau dari perspektif kepemimpinan pendidikan Islam perlu dilakukan the real actions oleh semua pemangku kepentingan (stakeholders), baik di lembaga pendidikan formal, non formal, maupun informal. Barangkali bisa dijadikan contoh the real action dari hasil studi Lubis (2015) menemukan bahwa pondok pesantren sebagai lembaga pendidikan non formal dengan sistem pembelajarannya yang khas dan cenderung demokratis telah memberikan kontribusi positif dalam membina para santri sebagai calon-calon generasi Islam yang memiliki perilaku demokratis, wawasan, pemahaman keagamaan, dan ta'at menjalankan ajaran agamanya (religious Islamic generation)..$^{41}$

Hasil studi berikutnya dari Lubis (2016) menemukan bahwa pondok pesantren telah ikut berperan aktif dalam revolusi mental dengan mendidik ribuan santri dengan mengedepankan sistem pembelajaran demokratis dan telah melahirkan para alumni yang memiliki mental rahmatan lil 'alamin, berakhlak mulia, serta menjunjung tinggi nilai-nilai ketuhanan dan kemanusiaan. ${ }^{42}$

${ }^{39} \mathrm{http}: / / \mathrm{www}$. gomarketingstrategic com/2016/11/apa-pengertiankepemimpinan-demokratis.html. Diunggah tanggal 4-10-2017.

${ }^{40} \mathrm{http} / /$ thoifahasriandini.blogspot.co.id/2015/10/contoh-pemimpindengan-gaya.html. Diunggah tanggal 4-10-2017.

${ }^{41}$ Mawardi Lubis, "The Pesantren Educational Management and Building Religious Islamic Generation", Nuansa Vol. VIII (2), Bengkulu : Program Pascasarjana IAIN Bengkulu, 2015, h. 126.

${ }^{42}$ Mawardi Lubis, "The Involving Boarding School In Mental Revolutian", Nuansa Vol. IX (2), Bengkulu : Program Pascasarjana IAIN Bengkulu, 2016, hh. 105-106.
Danim (2010) menggunakan istilah "kaderisasi kepemimpinan" yang dikaitkan dengan pengembangan profesi dan karir dengan istilah promosi bagi guru, seperti merujuk pada penugasan tambahan sebagai pemimpin dalam satuan pendidikan (kepala sekolah). Bahkan hal ini secara regulasi digariskan dalam UU No. 14 Tahun 2005 bahwa guru boleh menduduki jabatan struktural dan selanjutnya diatur dalam PP 74 Tahun 2008 Tentang Guru. ${ }^{43}$

Istilah lain yang digunakan Danim (2010), kaitannya dengan the real action dalam rangka mempersiapkan pemimpin pendidikan dengan istilah “pembudayaan kepemimpinan". Ia mengatakan bahwa di Amerika, pembudayaan kepemimpinan guru di awal karir mereka didukung oleh banyak peneliti. Katzenmeyer dan Moller (dalam Danim, 2010) menyatakan bahwa pengembangan kepemimpinan guru harus dimulai dari program prajabatan di universitas. Kurikulum dan pengalaman lapangan harus disusun dengan sebaik mungkin sehingga menekankan pada tanggung jawab seorang guru terhadap perbaikan sekolah dan mendorong guruguru mulai mengambil peran kepemimpinan terbatas pada awal karir mereka. ${ }^{44}$

Young (2010), Executive Director of the University Council for Eductional Administration (UCLA) menyatakan bahwa dalam mepersiapkan pemimpin pendidikan demokratis perlu kerjasama yang solid dari seluruh civitas akademika perguruan tinggi dengan melakukan sebuah program konkrit yang didesain sedemikian rupa dengan pola pelatihan kepemimpinan demokratis baik teoritis maupun praktis bagi mahasiswa. ${ }^{45}$

Model pembelajaran kooperatif dan kolaboratif barangkali dapat dijadikan sebagai model pembelajaran yang dapat membantu peserta didik untuk terbiasa berperilaku demokratis dan pada gilirannya nanti mereka akan menjadi calon-calon pemimpin demokratis. Belajar kooperatif adalah belajar dengan cara bekerja sama untuk mencapai tujuan secara efektif dan efisien. Sedangkan belajar kolaboratif adalah kerja bersama dengan orang lain dalam proyek bersama, kerja bersama sebagai aliansi strategis. Model ini sangat menghargai perbedaan intelektual. ${ }^{46}$

\footnotetext{
${ }^{43}$ Sudarwan Danim, Kepemimpinan Pendidikan, ... h. 178

${ }^{44}$ Sudarwan Danim, Kepemimpinan Pendidikan, ... h. 179.

${ }^{45} \mathrm{http} / / / \mathrm{www}$. academia.edu/26511973/ Preparing-Democratic-Education-leaders. Diunggah tanggal 5-10-2017.

${ }^{46}$ Tim Penyusun dosen Fakultas Tabiyah IAIN Plembang, Materi Pendidkkan dan Pelatihan Guru (PLPG), (Palembang : IAIN Palembang, 2012), h..50.
} 
Mawardi Lubis | Preparing Of Democratic Education Leaders 114

Jadi, untuk mempersiapkan pemimpin pendidikan demokratis dalam perspektif kepemimpinan pendidikan Islam perlu adanya the real action program terutama di lembaga-lembaga pendidikan formal. Program ini didesain sedemkian rupa dengan fokus kepada kegiatan konkrit yang menekankan kepada pendidikan dan latihan kepemimpinan demokratis Islami dan pada setiap komponen aktivitas pendidikan juga ditekankan aspek kepemimpinan demokratis Islami teoretis dan praktis. Artinya, peserta didik dibekali dengan teori-teori kepemimpinan demokratis Islami dan selanjutnya mereka dibimbing dan dilatih untuk praktik simulasi memimpin rapat, musyawarah, diskusi, dan lain sebagainya.

\section{Penutup}

Dalam rangka mempersiapkan pemimpin pendidikan demokratis dalam perspektif kepemimpinan pendidikan Islam perlu adanya the real action program terutama di lembaga-lembaga pendidikan formal. Program ini didesain sedemkian rupa dengan fokus kepada kegiatan konkrit yang menekankan kepada pendidikan dan latihan kepemimpinan demokratis Islami dan pada setiap komponen aktivitas pendidikan juga ditekankan aspek kepemimpinan demokratis Islami dengan mengacu kepemimpinan Rasulullah saw baik secara teoretis maupun praktis. Artinya, peserta didik dibekali dengan teoriteori kepemimpinan demokratis Islami dengan mencontoh kepemimpinan Rasulullah saw dan selanjutnya mereka dibimbing dan dilatih untuk praktik simulasi memimpin rapat, musyawarah, diskusi, dan lain sebagainya.

\section{Daftar Pustaka}

Al-Qur'anulkarim

Bahreisy, Salim (1986), Riyadhus shalihin (Terjamahan Jilid I), Bandung : PT. Alma'arif

Danim, Sudarwan (2010) Kepemimpinan Pendidikan, Bandung : Alafabeta

http://www.gomarketingstrategic.com/2016/11/ apa-pengertian-kepemimpinan-demokratis. html. Diunggah tanggal 4-10-2017. http://thoifahasriandini.blogspot.co.id/2015/10/ contoh-pemimpin-dengan-gaya.html. Diunggah tanggal 4-10-2017.

https :://journaal.unesa.ac.id/index.php/jptt/article/download/1390/960. Diunggah tanggal 4-10-2017.

http://www.academia.edu/26511973/ PreparingDemocratic-Education-leaders. Diunggah tanggal 5-10-2017.

Lubis, Mawardi (2010) “Implementasi Nilai-nilai Islami melalui MBS pada MAN model Bengkulu,' Sosio-Religia, vol. 9 (2) Yogyakarta

Lubis, Mawardi, M. Syakroni dan Moch. Dahlan (2012) "Perilaku Kepemimpinan Kepala Madrasah Perempuan" (studi kasus di MTs Mambaul Ulum Kec. Pondok Kubang Kab. Bengkulu Tengah), Manhaj Vol. 12 (1) Bengkulu

Lubis, Mawardi (2013) "Pengaruh Gaya Kepemimpinan Kepala Sekolah, Partisipasi Komite Sekolah, dan Soliditas Guru Terhadap Efektivitas Pengelolaan SD Negeri se-Kota Bengkulu,' Disertasi (Tidak dipublikasikan)

Lubis, Mawardi (2015) “The Pesantren Educational Management and Building Religious Islamic Generation,' Nuansa Vol. VIII (2), Bengkulu : Program Pascasarjana IAIN Bengkulu

Lubis, Mawardi (2016) "The Involving Boarding School In Mental Revolutian,' Nuansa Vol. IX (2), Bengkulu : Program Pascasarjana IAIN Bengkulu

Purwanto, Nagalim (2005), Administrasi dan supervisi pendidikan, Bandung : PT. Remaja Rosdakarya

Qomar, Mujamil (2007), Manajemen pendidikan Islam, Malang : Erlangga

Supriadi, Oding (2010) Rahasia Sukses Kepala Sekolah, Yogyakarta : LaksBang

Tim Penyusun dosen Fakultas Tabiyah IAIN Plembang (2012), Materi Pendidkkan dan Pelatihan Guru (PLPG), Palembang : IAIN Palembang 
Mawardi Lubis | Preparing Of Democratic Education Leaders 